\title{
Study on the Underwriting Circle of Property-Liability Insurance Market under Competition
}

\author{
Wang Yunpeng \\ Central University of Finance and Economies \\ China Institute for Actuarial Science
}

\begin{abstract}
The paper models the competition between non-life insurers within the framework of game theory and solve the Nash equilibrium with software $R$. The dynamic game where insurers compete in multiple periods shows the characteristic of underwriting cycle, which has been tested in the non-life insurance markets of many countries. Whereas the theoretical explanation for the existence of underwriting cycle is not settled, the paper contributes an additional explanation. With 1000 simulations of the dynamic game, shows the. The length of the underwriting cycle is distributed in 7 to 8 years.
\end{abstract}

Key words: Underwriting cycle, Insurance market, Nash equilibrium

\section{INTRODUCTION}

Among the topics regarding insurance market, the underwriting cycle of the market is a critical issue that attracts the attention of scholars from different countries. The phenomenon is more apparent in the property-liability market, as indicated by the volatility of the combined ratio. From the pattern of the combined ratio of the Australian property-liability insurance market, Taylor (1986) reveals that the pricing behavior of the insurers is affected by the market. Cummins and Outreville (1987) empirically analyzes the underwriting cycle of the propertyliability insurance market with the combined ratio. According to the China Insurance Yearbook (2010-2016), we summarize the financial status of the Chinese property-liability insurance market in Table 1. From the table, the combined ratio of the market exhibits the pattern of a cycle: decrease followed by increase and a further decrease follows the increase. Li (2011), Wu and $\mathrm{Su}$ (2014) empirically analyzed the underwriting cycle of the Chinese property-liability insurance market and concludes that the length of the cycle (LC) is between 7.66 and 10.77 years and the LC of the different insurance product is between 4 and 8 years.

Table 1 The financial status of the property-liability insurance market

\begin{tabular}{|c|c|c|c|c|c|c|c|}
\hline & 2009 & 2010 & 2011 & 2012 & 2013 & 2014 & 2015 \\
\hline Net Premium Written & 2875.83 & 4026.89 & 4779.06 & 5530.10 & 6481.20 & 7546.14 & 7994.97 \\
\hline Losses Incurred & 1575.78 & 1756.03 & 2262.81 & 2917.10 & 3554.20 & 3788.21 & 4194.17 \\
\hline Administration Costs & 521.21 & 675.55 & 893.70 & 1066.08 & 1240.97 & 1410.27 & 1644.03 \\
\hline Commission & 386.13 & 277.33 & 364.48 & 645.97 & - & - & - \\
\hline Net Underwriting Gain/Loss & -99.37 & 83.59 & 176.65 & 125.61 & 22.00 & 42.60 & 99.56 \\
\hline Net Investment Income & - & - & - & - & 413.19 & 763.26 & 922.47 \\
\hline Net Income after Taxes & 16.76 & 178.49 & 234.45 & 257.36 & 268.25 & 520.49 & 630.94 \\
\hline Combined Ratio & 104.46 & 97.33 & 95.26 & 97.15 & 99.50 & 99.31 & 98.61 \\
\hline
\end{tabular}

There are plenty research on the existence of the underwriting cycle. Venezian (1986), Cummins and Outreville (1987), Doherty and Kang (1988), Grace and Hotchkiss (1995), Merei 
(2006) studied on the underwriting cycle of the US property-liability insurance market. The main conclusion is that there is underwriting cycle in the market and LC is around 6 to 8 years. However, with respect to the theoretical explanation of the underwriting cycle, there is no common agreement.

Feldblum (2001) argues that there are four factors that lead to the underwriting cycle, including actuarial pricing, underwriting philosophy, interest rate volatility and market competition strategy. With respect to actuarial pricing, Venezian (1986) propose the principle of loss extrapolation in that the insurers are assumed to rely on past data in insurance pricing, but the past data cannot reflect the future loss precisely because of the uncertainty of the losses incurred and the lag of the information because of accounting, regulation and legal standard, so the actuarial pricing volatiles around the risk premium. Niehaus and Terry (1993) further proves that the volatility of the market results from the fact that the insurance companies predict future losses from the past data.

Underwriting philosophy affects the insurers from the aspect of the control of the underwriting behavior and the incompatibility of operating strategy. Winter (1989) argues that the ability to supply in the insurance market strongly depends on the financial status of the insurance company. If the insurer has surplus in internal capital, the company will expand the supply, vice versa. External capital is costly and is not readily available, so the constraint of capital restricts the underwriting ability of the insurer. Myers (1994) points out that due to the uncertainty of the future loss level, insurance company will reduce the underwriting capacity when there is a lack of internal capital, instead of seeking for external capital.

With respect to the interest rate volatility, Field and Venezian (1989) argues that the volatility will impact on the investment of the insurer and the premium discount for the potential insurance consumers and thus affect the frequency and length of the insurance cycle. Myers and Cohn (1987) proposes that insurance premium is the present value of future losses and expenses, so the higher the discount rate, the lower the insurance premium. Doherty and Kang (1998) and Cummins, etc (1991) argues that high interest rate leads to high investment rate, so increase of cash flow will enable insurers to cut the premium rate.

With respect to the operating strategy of the insurance companies, Radach (1988) deems that insurance companies cannot keep complete rationality under the competition pressure and they tend to keep the market share with the price war and over insurance on risks. Wilson (1981) and Berger (1988) argues that the underwriting cycle results from over competition and the following insolvency and reduced market supply. Meanwhile, the pricing behavior of the insurance companies is inseparable from the market price, which does not depend on a single company (Feldblum, 2001). Several papers model the operating strategy of the insurance companies, including Taylor (1986), Powers and Shubik (1998), where insurers maximizes their profit in making pricing decisions. However, none of the paper takes into account the interaction between the insurers. Dutang (2013) models the competition between the insurers with game theory and solves explicitly the pricing strategy of the insurers under Nash equilibrium.

This paper will look into the underwriting cycle with respect to the operating strategies, with the utilization of the model proposed by Dutang (2013). In the model of the competition of insurers, the parameter will be updated according to the game of the last period. We then verify the existence of the underwriting cycle from the analysis of the market price in each period. The rest of the paper is organized as follows: Section 2 develops the one-period 
noncooperative game of this paper. Section 3 presents the model parameters and the dynamic model. Section 4 presents the model results while Section 5 concludes.

\section{A one-period model}

Dutang (2013) proposed the one-period game model in his paper, which captures the competition of the insurance companies in the property-liability insurance market. The model is constructed under the framework of game theory, where there the objective function and the constraint function are necessary for the solvation of the Nash equilibrium. Before we look into detail of the model, we first introduce the concept of Nash equilibrium. For a game with $I$ players, $O_{j}$ is the objective function which the players seek to maximize, and $X_{j}$ is the feasible set where the players can choose their operating strategy from. Then Nash equilibrium is a vector $x^{*}=\left(x_{1}^{*}, \ldots, x_{I}^{*}\right)$, so that for all $j=1, \ldots, I, x_{j}^{*}$ is the solution to $\sup _{x_{j} \in X_{j}} O_{j}\left(x_{j}, x_{-j}^{*}\right)$, where $x_{j}$ and $x_{-j}^{*}$ represent the strategy of the insurer $j$ and other insurers. The feasible set of insurer $j$ is $X_{j}=\left\{x_{j}, g_{j}\left(x_{j}\right) \geq 0\right\}$, where $g_{j}\left(x_{j}\right)$ is the constraint function. Thus, Nash equilibrium is an equilibrium point: given the strategies of other insurers, the insurer has no motivation to deviate from the equilibrium.

In the game model, there are $I$ insurers selling insurance product to $n$ consumers. The consumers chooses different insurers according to the price offered and have no bargaining power of the price. The insurers make insurance pricing to maximize the objective function, usually their profit, under the constraints. Next we'll display the model briefly, and we guide the interested readers to Dutang (2013).

\subsection{Consumer Choice Model}

We assume the insurance market to be with $n=10000$ insurance consumers. At the upfront of the game, each insurer is assigned a certain amount of consumers $n_{j}$. After the insurers have set their pricing, the consumers choose the insurers according to the consumer choice model. The transfer probability from insurer $j$ to $k$ is as follows.

$$
p_{j \rightarrow k}= \begin{cases}\frac{1}{1+\sum_{j_{\neq}} e^{f_{j}\left(x_{j}, x_{l}\right)}} \text { if } j=k \\ \frac{e^{f_{j}\left(x_{j}, x_{i}\right)}}{1+\sum_{\neq j} e^{f_{j}\left(x_{j}, x_{i}\right)}} \text { if } j \neq k\end{cases}
$$

Where $f$ is the price-sensitivity function with two forms $\bar{f}_{j}\left(x_{j}, x_{l}\right)=\bar{u}_{j}+\bar{\alpha}_{j} \frac{x_{j}}{x_{l}}$ and $f_{j}^{\prime}\left(x_{j}, x_{l}\right)=\theta \rho+\theta \%\left(x_{j}-x_{l}\right)$. We can see from the model that $\sum_{k} p_{j \rightarrow k}(x)=1$.

The portfolio size $N_{j}(x)$ of insurer $j$ depends on the decision of policyholders of its own portfolio and other insurers and the expectation of $N_{j}(x)$ is

$$
E\left(N_{j}(x)\right)=n_{j} \times p_{j \rightarrow j}(x)+\sum_{\not \neq j} n_{l} \times p_{l \rightarrow j}(x)
$$




\subsection{Loss model}

We assume that in the one-period game, the claims are paid at the end of the year. Let $Y_{i}$ represent the aggregate loss of policy $I$ within the period. Then $Y_{i}=\sum_{i=1}^{M_{i}} Z_{i, l}$ where $M_{i}$ is the claim frequency of policyholder $i$ and $\left(Z_{i, l}\right)_{i}$ is the claim amount. The total loss incurred of insurer $j$ is $S_{j}(x)=\sum_{i=1}^{N_{j}(x)} Y_{i}=\sum_{i=1}^{N_{j}(x)} \sum_{i=1}^{M_{i}} Z_{i, l}$. Assume that $Y_{i}$ is i.i.d., and $M_{i}$ follows Possion distribution $\mathrm{P}\left(N_{j}(x) \lambda\right)$.

\subsection{Objective function}

In the model, we assume that the insurers are setting their goal as maximizing profit level and the profit depends on two aspects: the portfolio size of the insurer and the profit level per insurance policy. In the model, the form of the demand function is

$$
D_{j}(x)=\frac{n_{j}}{n}\left(1-\beta_{j}\left(\frac{x_{j}}{m_{j}(x)}-1\right)\right)
$$

where $\beta_{j}>0$ is the elasticity parameter and $m_{j}(x)$ represents the market premium. The logic behind the demand function is that if the price offered by insurer $j$ is higher than the market premium, the policyholders tend to withdraw from the current insurer and insure at other companies. Thus, $D_{j}(x)$ is an approximate to the market share $E\left(N_{j}(x)\right) / n$. The market premium $m_{j}(x)$ in (3) is the mean price of other competitors

$$
m_{j}(x)=\frac{1}{I-1} \sum_{k \neq j} x_{k}
$$

The profit level per insurance policy depends on the differenexpecce between the insurance premium and the loss expectation. We define $\pi_{j}$ as

$$
\pi_{j}=\omega_{j} \bar{a}_{j, 0}+\left(1-\omega_{j}\right) \bar{m}_{0}
$$

where $\bar{a}_{j, 0}$ is the actuarial premium of insurer $j$ based on the past loss experience, $\bar{m}_{0}$ is the market premium. $\omega_{j} \in[0,1]$ is the confidence level of insurer $j$ in its own loss experience.

The objective of the insurer is the product of the demand function and profit per policy:

$$
O_{j}(x)=\frac{n_{j}}{n}\left(1-\beta_{j}\left(\frac{x_{j}}{m_{j}(x)}-1\right)\right)\left(R_{j} x_{j}-\pi_{j}\right)
$$

where $R$ is the total investment return of insurer $j$, since insurer $j$ is able to invest the premium collected. In setting the insurance premium, the insurer needs to balance the profit per policy and the portfolio size of the company.

\subsection{Solvency constraint}

One important feature of the game of insurers is the need to keep the capital above the solvent level, so as to protect the policyholders from the bankruptcy of the insurance company. The solvency constraint is set as follows

$$
g_{j}^{1}\left(x_{j}\right)=\frac{K_{j}+n_{j}\left(R x_{j}-\pi_{j}\right)\left(1-e_{j}\right)}{k \sigma(Y) \sqrt{n_{j}}}-1
$$

where $k$ is the solvency coefficient chosen to approximate a $99.5 \%$ quantile and $e_{j}$ is the expense rate. The numerator corresponds to the sum of the current capital $K_{j}$ and the expected profit on the portfolio of the insurer, whereas the denominator measures the required capital. The constraint is equivalent to $K_{j}+n_{j}\left(R x_{j}-\pi_{j}\right)\left(1-e_{j}\right) \geq k \sigma(Y) \sqrt{n_{j}}$.

In practice, regulation usually imposes constraints on the maximum and minimum of the insurance price. We model the constraints as follows: 


$$
\begin{array}{cc} 
& g_{j}^{2}\left(x_{j}\right)=1-\mathrm{e}^{-\left(x_{j}-x_{\min }\right)} \geq 0, \quad g_{j}^{3}\left(x_{j}\right)=1-\mathrm{e}^{-\left(x_{\max }-x_{j}\right)} \geq 0 \\
\text { where } & x_{\min }=\mathrm{E}(Y) /\left(1-e_{\min }\right)<x_{\max }=3 \mathrm{E}(Y)
\end{array}
$$

and $e_{\min }$ is the minimum expense ratio.

Overall, the constraints of insurer $j g_{j}\left(x_{j}\right)=\left(g_{j}^{l}\left(x_{j}\right)\right)_{1 \leq l \leq 3}$ is

$$
\left\{x_{j}, g_{j}\left(x_{j}\right) \geq 0\right\}=\left\{x_{j} \in\left[x_{\min }, x_{\max }\right], K_{j}+n_{j}\left(x_{j}-\pi_{j}\right)\left(1-e_{j}\right) \geq k_{995} \sigma(Y) \sqrt{n_{j}}\right\}
$$

\subsection{Game sequence}

Given the objective function in (6) and solvency constraints in (11), the sequence of the game is as follows:

(i) The insurers set their premium according to a Nash equilibrium $x^{*}$;

(ii) Policyholders randomly choose their new insurer according to probabilities $p_{k \rightarrow j}$ and we get $N_{j}\left(x^{*}\right)$;

(iii) For the one-year coverage, claims are random according to the frequency-average severity model relative to the portfolio size $N_{j}\left(x^{*}\right)$;

(iv) The profit of the insurer $j$ is $P_{j}\left(x^{*}\right)=N_{j}\left(x^{*}\right) R x^{*}\left(1-e_{j}\right)-S_{j}\left(x^{*}\right)$ and new capital is $K_{j}+U W_{j}\left(x^{*}\right)$, where $e_{j}$ is the expense rate and $K_{j}$ the initial capital value.

(6) Properties and solvation of the premium equilibrium

According to proposition 2.1 and 2.3 of Dutang (2013), the model has unique Nash equilibrium. We solve the Nash equilibrium with package GNE in R. Nash equilibrium cannot be solved directly with mathematical methods, so a reformulation is necessary, including the complementary reformulation, constraint equation reformulation, quasi-variation equation reformulation and Nikaido Isoda reformulation, etc. In package GNE, the reformulation and the corresponding algorithms are realized. We solve the Nash equilibrium in the paper is by complementary reformulation. For interested readers, please look up Dutang (2012).

\subsection{Model parameters}

\section{THE ONE-PERIOD GAME}

In the model, we assume that there are ten insurers and there are 10000 potential policyholders in the insurance market. Initially, the market share of the insurers is $(3861,2243,1295,694,543,370,358,231,220,185)$, which approximates the actual market share of the largest ten insurers in Chinese property-liability insurance market. We set the Possion Lognormal distribution so that $\mathrm{E}(Y)=1$ and $\sigma(Y)=4.472$. The confidence level used to calculate the risk premium is $\omega_{j}=0.9$. The actuarial based premium and the market premium of the first period, $\bar{a}_{j, 0}$ and $\bar{m}_{0}$ respectively is chosen as in Table 1 . Then we can calculate risk premium $\pi_{j}$, as displayed in Table 1. The parameter in the consumer choice model is set in Table 2 . We determine the parameter in the way that given the price vector of $x^{1}=(1,1,1,1,1,1,1,1,1,1)$ and $x^{1.05}=(1.05,1,1,1,1,1,1,1,1,1)$, the lapse rate of the insurer 1 is $1-p_{1 \rightarrow 1}\left(x^{1}\right)=10 \%$ and $1-p_{1 \rightarrow 1}\left(x^{1.05}\right)=15 \%$ (we show the lapse rate for each insurer in Table 4). The price sensitivity parameter $\beta_{j}$ of the objective functions are fitted using $1-\beta_{j}\left(x_{j} / m_{j}(x)-1\right) \approx p_{j \rightarrow j}(x)$ and we show the value of $\beta_{j}$ in Table 4 . We assume that the insurers have the initial capital so that the solvency level is $150 \%$. For each insurer, the expense rate is set as $(0.34,0.36,0.38,0.39,0.40,0.41,0.42,0.43,0.44,0.45)$. The difference between the expense rate reflects the fact that the insurers with larger portfolio size have lower expense rate in Chinese property-liability insurance market. Assume that the regulation imposes the minimum expense rate to be $15 \%$, ie $e \min =15 \%$. As for the total investment return of the insurers, we obtain the historical investment rate of the Chinese 
insurance industry, as displayed in Table 5, and run Monte Carlo simulation with respect to the mean and standard deviation of the historical investment rate for each insurer in each year.

Table 2 Premium parameter $\bar{a}_{j, 0}, \bar{m}_{0}$ and $\pi_{j}$

\begin{tabular}{|c|c|c|c|c|c|c|c|c|c|c|}
\hline PLN & P1 & P2 & P3 & P4 & P5 & P6 & P7 & P8 & P9 & P10 \\
\hline $\bar{a}_{j, 0}$ & 1.515 & 1.563 & 1.613 & 1.639 & 1.667 & 1.695 & 1.724 & 1.754 & 1.786 & 1.818 \\
\hline$\pi_{j}$ & 1.531 & 1.574 & 1.619 & 1.643 & 1.668 & 1.693 & 1.719 & 1.747 & 1.775 & 1.804 \\
\hline $\bar{m}_{0}$ & \multicolumn{10}{|c|}{1.677} \\
\hline
\end{tabular}

Table 3 Lapse parameter $\bar{u}_{j}, \bar{\alpha}_{j}, \phi \%, \theta \rho$

\begin{tabular}{|c|r|r|r|r|r|r|r|r|r|r|}
\hline & \multicolumn{1}{|c|}{ P1 } & \multicolumn{1}{c|}{ P2 } & \multicolumn{1}{c|}{ P3 } & \multicolumn{1}{c|}{ P4 } & \multicolumn{1}{c|}{ P5 } & \multicolumn{1}{c|}{ P6 } & \multicolumn{1}{c|}{ P7 } & \multicolumn{1}{c|}{ P8 } & P9 & \multicolumn{1}{c|}{ P10 } \\
\hline $\bar{u}_{j}$ & -13.65 & -11.32 & -9.87 & -9.73 & -9.59 & -9.46 & -9.34 & -9.22 & -9.10 & -8.99 \\
\hline $\bar{\alpha}_{j}$ & 9.25 & 7.31 & 6.16 & 6.05 & 5.95 & 5.85 & 5.75 & 5.66 & 5.58 & 5.50 \\
\hline$\not \rho \rho$ & -4.39 & -4.01 & -3.71 & -3.68 & -3.65 & -3.62 & -3.58 & -3.55 & -3.52 & -3.49 \\
\hline$\not \rho$ & 9.25 & 7.31 & 6.16 & 6.05 & 5.95 & 5.85 & 5.75 & 5.66 & 5.58 & 5.50 \\
\hline
\end{tabular}

Table 4 Lapse rate

\begin{tabular}{|c|c|c|c|}
\hline \multirow{2}{*}{ Insurer } & \multicolumn{2}{|c|}{ Lapse rate } & \multirow{2}{*}{$\beta_{j}$} \\
\cline { 2 - 3 } & $x^{1}$ & $x^{1.05}$ & \\
\hline 1 & $10 \%$ & $15 \%$ & 3.0 \\
\hline 2 & $14 \%$ & $19 \%$ & 3.8 \\
\hline 3 & $18 \%$ & $23 \%$ & 4.6 \\
\hline 4 & $18.5 \%$ & $23.5 \%$ & 4.7 \\
\hline 5 & $19 \%$ & $24 \%$ & 4.8 \\
\hline 6 & $19.5 \%$ & $24.5 \%$ & 4.9 \\
\hline 7 & $20 \%$ & $25 \%$ & 5.0 \\
\hline 8 & $20.5 \%$ & $25.5 \%$ & 5.1 \\
\hline 9 & $21 \%$ & $26 \%$ & 5.2 \\
\hline 10 & $21.5 \%$ & $26.5 \%$ & 5.3 \\
\hline
\end{tabular}

Table 5 Historical investment rate of Chinese insurance market

\begin{tabular}{|l|l|l|l|l|l|l|}
\hline Year & 2011 & 2012 & 2013 & 2014 & 2015 & 2016 \\
\hline $\begin{array}{l}\text { Investment } \\
\text { rate }\end{array}$ & $3.6 \%$ & $3.39 \%$ & $5.04 \%$ & $6.3 \%$ & $7.56 \%$ & $5.66 \%$ \\
\hline
\end{tabular}

The difference between the lapse rates reflects the fact that in Chinese property-liability insurance market, the policyholders tend to choose the larger insurers because of the brand effect and better service provided.

\subsection{Result of the one-period game}

Using the package GNE in R, we can obtain the Nash equilibrium of the ten insurers, which is displayed in Table 6. $\Delta_{j}$ represents the change of portfolio, while $\rho_{j}$ represents the solvency level and $p_{j}$ reflects the profit of the insurer. 
Table 6 Nash equilibrium

\begin{tabular}{|c|c|c|c|c|}
\hline Insurer & $x_{j}^{*}$ & $\Delta_{j}$ & $\rho_{j}$ & $p_{j}$ \\
\hline 1 & 1.940 & -345 & $333 \%$ & 1398 \\
\hline 2 & 1.899 & -170 & $306 \%$ & 914 \\
\hline 3 & 1.880 & -59 & $280 \%$ & 594 \\
\hline 4 & 1.887 & 42 & $179 \%$ & 121 \\
\hline 5 & 1.894 & 62 & $212 \%$ & 232 \\
\hline 6 & 1.902 & 88 & $174 \%$ & 113 \\
\hline 7 & 1.910 & 82 & $202 \%$ & 189 \\
\hline 8 & 1.919 & 103 & $178 \%$ & 131 \\
\hline 9 & 1.928 & 98 & $139 \%$ & 35 \\
\hline 10 & 1.938 & 99 & $110 \%$ & -25 \\
\hline
\end{tabular}

The result of the Nash equilibrium demonstrates that the equilibrium premium is much higher than the risk premium $\pi_{j}$. Insurer 1's price is the highest, which reflects its competition advantage over the other insurers. Although the strategy of insurer 1 leads to reduction of the portfolio, the high profit per policy compensates the whole profit, so the profit of insurer 1 is the highest. The medium insurers adopts the fierce competition strategy so that the reduction of the portfolio will be less. The small insurers enjoy reinsure of the policyholders from large insurers, so they can set a relatively high premium. Due to the random claim amount, the trend of profit level is not clear in among the ten insurers. We should note that the profit level takes into account of the investment return. Insurer 10 suffers a loss in the one-period game and the solvency level approaches the regulatory line $100 \%$ and the regulation could take actions against the insurer should the solvency level decreases further to be under $100 \%$.

\section{THE DYNAMIC GAME}

In the dynamic game, the insurers will run into a multi-period game, where the result of each period is fed into the next period, which simulates the practical operation of the insurers. With the accumulation of historical data, the insurers will set operating strategies in each period according to the status of each insurer. The accumulation of data is modelled in the way as follows.

The accumulation of insurance claim. In each period, we use Monte Carlo simulation to simulate the total loss of the insurer based on the Possion Lognormal model and the portfolio size of the insurer. In practice, the insurer will predict the future claim cost according to the historical data. In our dynamic model, we assume the insurer will approximate the risk premium with the average cost of each policy in the last $t$ periods. The logic of the $t$ periods is that data from too long ago will be deemed as obsolete and will not be useful in predicting the future insurance claims. Since the claim amount is random, each insurer will have different experience of claim, which then affects the risk premium of the insurer.

The accumulation of capital. Each insurer is endowed with an initial amount of capital to satisfy the solvency level of $150 \%$ with respect to the initial market share. In each period, the insurer will make gains or losses based on the relation of the premium and the random claim. At the end of each period, the capital of the insurer will be updated to be the initial capital of the period, plus the premium and deduct the expense cost and insurance claim cost. Then, in the model, we will calculate the solvency level of each insurer. We consider the insurers whose solvency level are below 100\% to be insolvent and exclude them from the game thereafter. As for the portfolios of the insolvent insurers, we divide them among the survival insurers equally. 
In the one-period game, the insurers tend to price at a level higher than the risk premium, so the insurers are expected to accumulate more capital in the operation. In practice, the insurers could be insolvent because of large losses occurred, so are the insurers in our model.

The accumulation of market premium. Within the Nash equilibrium of each period, the insurers form a price vector, the average of which is the market premium of the period. When the insurer sets the price, they will impose a certain confidence level on the market premium. This pricing behavior models the emphasis the insurers put on the market premium. We assume that the insurer will take into account of the market premium of the recent $d$ periods with equal weights, since premium data from too long ago will be obsolete.

In the dynamic game model, we make the following assumptions: the insurers offer new products to the market and collect the premiums at the beginning of each year; the expense of the insurers happen at the beginning of each year; the payout of the insurance happens at the end of the year; the insurance claim is not affected by the inflation.

\section{MODEL RESULTS}

We model the dynamic game 1000 times and assume there is 25 periods in each simulation. In each period $t$ of the dynamic game, we will obtain the market premium $M_{t}$ by the average of all the premiums offered by the insurers in the market. In figure 1, we show the pattern of the market premium in 25 periods with two simulations, where the horizontal axis represents for the period and the vertical axis represents for the market premium. We can see from the figure that there is volatility in the market premium between each period under the Nash equilibrium of the insurers. In each simulation, the market premium shows different patterns. The difference occurs from the random insurance claims, which affect the risk premium of the insurer.

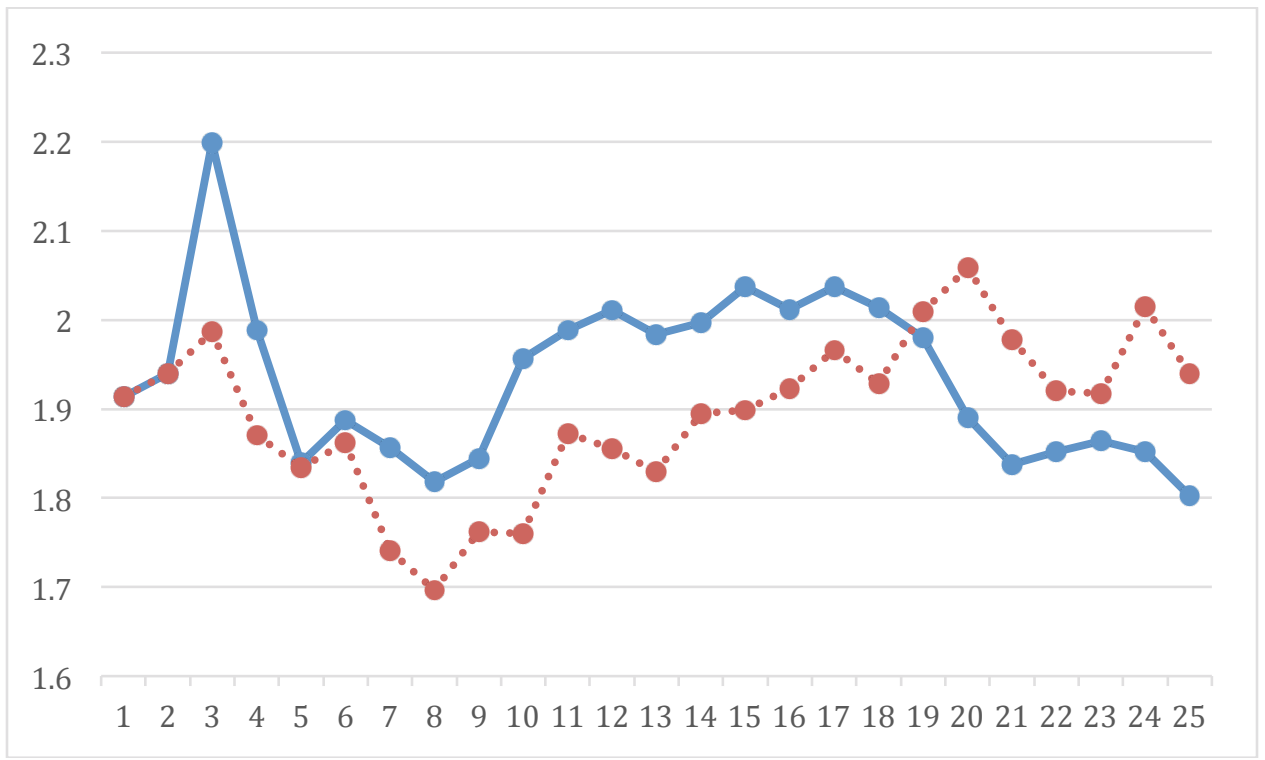

Figure 1 Market premium volatility of two simulations

As for the existence of the underwriting cycle, we make the judgement based on $\operatorname{AR}(2)$. The model for the $\mathrm{AR}(2)$ is as follows:

$$
M_{t}=m+a_{1}\left(M_{t-1}-m\right)+a_{2}\left(M_{t-2}-m\right)+\varepsilon_{t}
$$

where $M_{t}, M_{t-1}$ and $M_{t-2}$ is the market premium for period $t, t-1$ and $t-2$. The model is proposed by Cummins 和 Outreville (1987). We then verify the existence of the underwriting cycle by the 
conditions $a_{1}>0, a_{2}<0$ and $a_{1}^{2}+4 a_{2} \leq 0$. If the conditions are satisfied, the dynamic game shows the pattern of underwriting cycle and the length of the period is calculated by the formula $p=2 \pi \arccos \left(a_{1} /\left(2 \sqrt{-a_{2}}\right)\right)$.

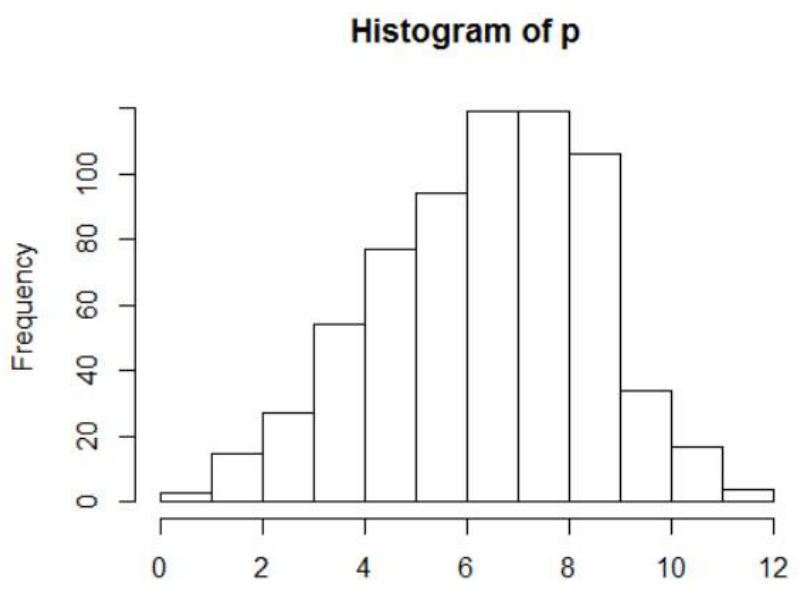

Figure 2 Histogram of length of underwriting cycle

Table 7 Statistics of the length of underwriting cycle

\begin{tabular}{|c|c|}
\hline & Length \\
\hline Minimum & 0.308 \\
\hline $\begin{array}{c}25 \% \\
\text { quantile }\end{array}$ & 4.923 \\
\hline Median & 6.533 \\
\hline Mean & 6.351 \\
\hline $\begin{array}{c}75 \% \\
\text { quantile }\end{array}$ & 7.930 \\
\hline Maximum & 11.690 \\
\hline
\end{tabular}

Figure 2 and Table 6 demonstrate the feature of the LC calculated in the model. In our 1000 simulations, there are 762 simulations that has the feature of underwriting cycle. In Figure 2, the horizontal axis represents LC while the vertical axis represents the frequency of the corresponding length. Figure 2 shows that LC is distributed between 4 and 9 periods mostly.

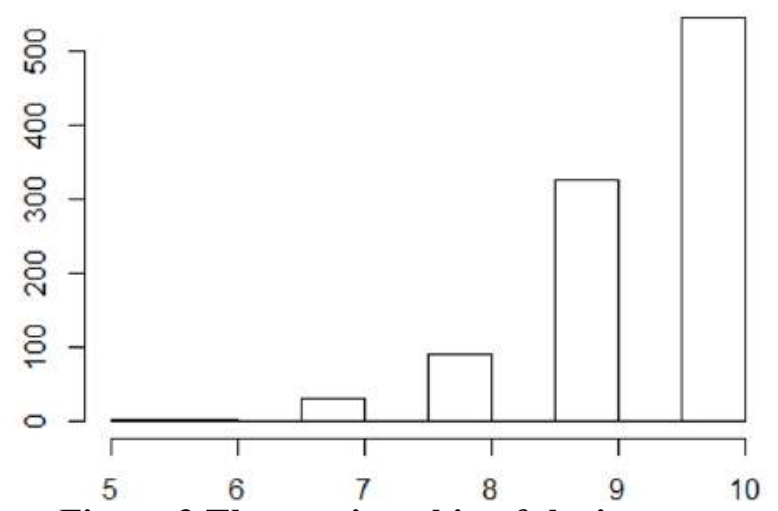

Figure 3 The survivorship of the insurers

Figure 3 shows how many insurers survive till the end of 25 periods. The number of 10 means that all the insurers stay solvent during the competition, while the number of 9 means that one insurer runs into insolvent in the simulation and so on. Most of the time, the competition is not 
so fierce that any insurer would run into insolvency. For around 100 simulations, there are more than 1 insurers that become insolvent.

\section{CONCLUSION}

The paper constructs one-period game model and the multiple period game model of the insurance companies. With the solvation of the game under Nash equilibrium, we obtain the operating strategy of the insurers and observe how the insurance market would evolve. Based on the game model proposed by Dutang (2013), we add the investment rate into the model and observe the competition in multiple periods. Our key findings are as follows.

(1)The operating strategy of the profit-maximizing insurers under the competition will lead to a price level higher than the risk premium, generating underwriting profit for the insurers. (2)In the multiple-period model, the randomness of the insurance claim affects the price level of each insurer and hence the market share, which will again affect the price. With the complexity of the relationship between the key operating variables of the insurers, the market premium of the insurance market demonstrates a feature of underwriting cycle. The model provides a theoretical explanation for the existence of the underwriting cycle. (3)During the competition, only few insurers would run into insolvency.

The model can be expanded in the following ways. (1)In practice, the non-life insurers usually have few underwriting profit and sometimes underwriting loss, so the insurers rely on investment return to compensate for the underwriting loss. The low price reflects that the insurers do not only set the profit as their operating objective, but also take into account the premium scale. The model could combine both the premium scale and the profit into the objective function. (2)Reinsurance is an important risk management tool for the insurer to mitigate the risk of large insurance claim and thus reduce the possibility of insolvency. The model could take into account the effect of reinsurance.

\section{References}

Asborne, M. \& Rubinstein, A., A course in game theory [M]. Massachusetts Institute of Technology, 2006.

Berger, Lawrence A., A Model for the Underwriting Cycle in Property-Liability Insurance Industry, Journal of Risk and Insurance, 1988(55): 298-306.

Cummins, J. David, Scott E. Harrington and Robert W. Klein, Cycles and Crises in Property-Casualty Insurance: Causes and Implications for Public Policy, Journal of Insurance Regulation, 1991: 50-93.

Dutang, C. A survey of GNE computation methods: theory and algorithms. Working paper, IRMA, 2012.

Dutang, C., Albrecher, H \& Loisel, S., Competition among non-life insurers under solvency constraints: A gametheoretic approach [J]. European Journal of Operational Research, 2013(231): 702-711.

Dutang, C. GNE: Computation of Generalized Nash Equilibria. R package version 0.97. 2012.

Kliger, D. \& Levikson, B., Pricing insurance contracts-An economic viewpoint. Insurance: Mathematics and Economics, 1998(3): 243-249

Li, L. S., Empirical analysis on the underwriting cycle of Chinese property-liability insurance industry based on Cummins-Outreville model, Insurance Studies, 2011(2): 40-47.

Polborn, M. K., A model of an oligopoly in an insurance market [J]. The Geneva Paper on Risk and Insurance Theory, 1998(1): 41-48.

Powers, M. R., \& Shubik, M., On the tradeoff between the law of large numbers and oligopoly insurance [J]. Insurance: Mathematics and Economics, 1998(2): 141-156.

Powers, M. R., \& Shubik, M., A “square-root rule” for reinsurance. The Journal of Risk Finance, 2006(2): 101-107.

Rees. R., Gravelle, H. \& Wambach, A., Regulation of insurance markets [J]. The Geneva Paper on Risk and insurance Theory, 1999(1): 55-68. 
Taylor, G. C., Underwriting Strategy in a competitive insurance environment [J]. Insurance: Mathematics and Economics, 1986(1): 59-77.

Taylor, G. C., Expenses and underwriting Strategy in competition [J]. Insurance: Mathematics and Economics, 1987(4): 275-287.

Zorich, V. Mathematical analysis I. Universitext (Vol. 1). Springer, 2000.

Cummins, J.D. and Outreville, J.F. (1987), An international analysis of underwriting cycles, Journal of Risk and Insurance, 1987(54): 246-62.

Venezian, E.C., Ratemaking Methods and Profit Cycles in Property and Liability Insurance, Journal of Risk and Insurance, 1986(52): 477-500.

Doherty, N.A. and Kang, H.B. (1988), Interest rates and insurance price cycles, Journal of Banking and Finance, 1988(12): 199-214.

Grace, M.F. and Hotchkiss, J.L., External impacts on property-liability insurance cycle, Journal of Risk and Insurance, 1995(62): 738-54.

Meier, U.B., Multi-national underwriting cycles in property-liability insurance, Part I: some theory and first empirical results, Journal of Risk Finance, 2006(7): 64-82.

Myers, S. S. and R. A. Cohn, “A Discounted Cash Flow Approach to Property-Liability Insurance Rate Regulation,” in Fair Rates of Return in Property-Liability Insurance, eds. J. D. Cummins and S. E. and Harrington, pp. 55-77, Dordrecht: Kluwer Nijhoff Publishing, 1987.

Feldblum, S., Underwriting cycles and business strategies, Proceedings of the Casualty Actuarial Society, LXXXVIII, 2001: 175-235.

Niehaus, G. and Terry, A., Evidence on the Time Series Properties of Insurance Premiums and Causes of the Underwriting Cycle: New Support for the Capital Market Imperfection Hypothesis. The Journal of Risk and Insurnace, 1993(60): 466-479.

Fields, J.A. and Venezian, E., Interest Rates and Profit Cycles: a Disaggregated Approach, Journal of Risk and Insurance, 1989(56): 312-319.

Radach, Floyd R., A Strategy for Cycle Management, Best's Review, 1988: 48-50

Wang, Y.P., Scale and Scope Economies of Chinese Property-liability Industry, Insurance Studies, 2016(12): 5-14.

Wilson, William C., The Underwriting Cycle and Investment Income, CPCU Journal, 1981(34): 225-232.

$\mathrm{Wu}, \mathrm{J}$. \& Su, F., Cyclicity of nonlife insurance products and a comparative analysis of influencing factors-based on insurance cycles and underwriting cycle theory, Insurance Studies, 2014(3): 30-41. 